\title{
Exploring the Relationship between Perceived Big Data Advantages and Online Consumers' Behavior: An Extended Hierarchy of Effects Model
}

\author{
Jean-Luc Pradel Mathurin Augustin ${ }^{1}, \&$ Shu-Yi Liaw ${ }^{2}$ \\ ${ }^{1}$ Department of Tropical Agriculture and International Cooperation, National Pingtung University of Science and \\ Technology, Pingtung City, Taiwan \\ ${ }^{2}$ Management College, Computer Centre, National Pingtung University of Science and Technology, Pingtung \\ City, Taiwan \\ Correspondence: Shu-Yi Liaw, National Pingtung University of Science and Technology, No 1, Hsueh-Fu Road, \\ Neipu Township, Taiwan.
}

Received: April 22, 2020

Accepted: May 9, 2020

Online Published: May 20, 2020

doi:10.5539/ibr.v13n6p73

URL: https://doi.org/10.5539/ibr.v13n6p73

\begin{abstract}
This study intends to extend the hierarchy of effects model into the reality of the tourism industry after incorporation of information and communication technologies. Data analyses were conducted on 260 online questionnaires. The findings indicated consumer behavior follows a three-layer model: Attention-Intention/Desire-Action/Sharing-Social Awareness. Among big data advantages, recommendation system, information search and improved customer service are important to Attention-Intention; information search, dynamic pricing are important to Desire-Action with customer service (lower significance level); only customer service is important to Sharing-Social awareness. This model allows understanding of consumers' behavior in online tourism as tourists are often sharing their experiences and raise awareness on service quality from e-vendors. Organizations might use big data to guarantee customers' satisfaction and attract positive feedback particularly from the third layer of behavior.
\end{abstract}

Keywords: online tourism, e-tourism, hierarchy of effects model, online consumer behavior, big data, big data advantages

\section{Introduction}

In the last few decades, rapid developments of information and communication technologies, the rise of social media platforms and the internet of things have completely changed how people socialize and communicate, how businesses seek to improve their consumer base and how information is accessed, used/consumed and spread around. In the past, consumers had very little access to information while making purchase decisions. The big data and big data analytics' era, the age of social media and mobile technologies have rendered data gathering easier than ever, but not providing any insights on data quality. Businesses, companies and organizations provide potential consumers with information that may eventually facilitate decision-making. This is achieved through the use of big data analytics. Therefore, thanks to big data analytics, online businesses and e-commerce companies might be able to take advantage of the important amount of information that streams online considering data are being generated on a regular basis. However, companies have to bear in mind the abundance of information represents a major risk of leading to information overload (Hemp, 2009). Dealing with an overwhelming amount of information from various sources might make customers' decision-making process harder than ever expected.

The rise of internet technologies has brought firms, industries, companies and even governments to the realization that perhaps an online presence is important. With said presence, businesses might be able to target the imposing number of potential consumers using new technologies such as mobile technology, the use of tracking devices, etc. Tourism has also been particularly influenced by recent technology developments considering that it is a service industry, thus explaining the existence of online tourism. Condratov (2013) noted that technology development offered tourists the possibility to identify, personalize and buy touristic products, but also offers the touristic industry globalization, generating ways for tourism agents to develop and distribute 
their offers globally. Given the continuously growing number of new technology users, it becomes evident that marketing models will be affected by the influence of the internet on consumers' behavior.

Back in 1898, St. Elmo Lewis proposed a hierarchical model that stipulated there were three important steps for success in advertisement and sale: attract attention, maintain interest and create desire (Barry, 2012; Strong, 1925). He later updated his model, adding a fourth step "get action" (Barry, 2012). Commonly known as the AIDA model (attention, intention, desire, action), this model is among the most used in the marketing and advertising field. Since its creation, the model has been widely utilized and was therefore subjected to many prior revisions. However, due to technology changes and the emergence of social media platforms per example, one can confidently assert that the model will be subjected to numerous future updates to cope with existing or future realities in the marketing and advertising world. This is among the reasons the present study will focus on finding out whether one or more layers might be added to the model, based on the relationship between perceived big data advantages and online consumers' behavior in the tourism industry.

Big data and big data analytics are widely used in e-commerce businesses these days, in an effort to fully take advantage of the new developments to better target and serve potential new customers or to retain and offer an improved service to old customers. In the online commerce or e-commerce literature, it is noted that tourism has become the number one e-commerce category with the largest amount of transactions (Harteveldt, Stark, Sehgal, \& van Geldrn, 2009; Pan, 2015). Pan (2015) further highlighted that tourism as an information intensive industry, requires the help of new technologies while it also influences their development.

The hierarchy of effects model was developed with the intent of representing four different steps taken into consideration by a seller to lead the customers toward the purchase decision. The end goal is for the seller to convince the customer to buy his products. Therefore, he tries to get customers' attention and have them show interest in the products/services offered, which would later translate into a desire and lead to the customer ultimately buying the products/services. Social media has emerged in the meantime, empowering customers by providing them with a way to voice their opinion. Everything is shared on social media nowadays and this is known by businesses and companies who are trying to take advantage of that situation, given their goal is to gather as many website visitors and try to turn them into actual customers. This situation has resulted in a shift in communication and marketing strategies from traditional businesses to e-businesses. Therefore, this study explores consumers' opinion about big data advantages in online tourism in an attempt to find whether there are more than two stages that apply to the hierarchy of effects model in the big data era.

The present study aims at exploring the layers of consumer behavior in an online tourism context under the influence of big data and big data analytics. After the number of layers has been figured out, the existence of a relationship between the two constructs will be examined. Moreover, the study intends to investigate the relationship between each perceived big data advantage and the layers of consumers' behavior in online tourism. This will help online service providers and e-businesses identify specific big data advantages able to trigger certain layers of behavior. In other words, if companies expect a certain action/reaction from their potential customers, they will definitely know which specific big data advantage(s) to focus on. It's particularly meaningful for organizations to have this kind of insights because such information is particularly important in the process of profit maximization. Throughout the literature, the focus has long been on identifying big data advantages and their importance for various industries; however there seems to be a lack of focus on how these advantages influence consumers' behavior.

\section{Big Data, Online Tourism and Hierarchy of Effects Model}

This section introduces the concept of big data and presents its advantages/disadvantages in relation to online consumers. It also explores the online tourism concept followed by an historical view of the development of the hierarchy of effects model. Lastly, the hypotheses formulated to conduct this study and its research model are presented.

\subsection{The Big Data Era}

The appearance of big data technologies was induced by progress in information and communication technologies such as the internet of things, the web 2.0, mobile technologies and the development of social network platforms. As a result of such technology advancements, massive amounts of data were generated on a daily and consistent basis. It became no longer possible to use the same and quickly obsolete techniques for data collection, processing, treatment and analysis (Constantiou \& Kallinikos, 2015). Finding ways to handle the ever increasing flux of data and information collected from various sources led to the era of big data and big data analytics. 
Big data is often referred to as the accelerated availability of information and data that has taken place since the development of internet technologies, which has later been accelerated with the social media era, the use of tracking devices, as well as mobile technologies. Various authors, instead of proposing a definition of the concept, opted to discuss its dimensions. The number of proposed definitions throughout the literature indicates big data is a relatively new concept, although extensively discussed lately. However, one proposed definition has garnered a lot of attention, and refers to three intrinsic characteristics of big data: "volume", "variety" and "velocity" (Laney, 2001). Since the introduction of the 3V's framework, it has often been used to describe and define big data (Chen, Chiang, \& Storey, 2012; Kwon, Lee, \& Shin, 2014); however other authors later discussed more dimensions of big data considering the rapidly evolving nature of the information collected as well as new technological changes (Liao, Yin, Huang, \& Sheng, 2014; Gandomi \& Haider, 2015; Shah, Rabhi, \& Ray, 2015; Zhong, Newman, Huang, \& Lan, 2016; Liaw \& Le, 2017). It is common belief that the 3V's laid the foundations for more complete, extended and thorough frameworks, and explains why dimensions such as "variability", "veracity" (Zicari, 2013) and "value" were added (Lee, 2017). Other dimensions not in line with the V framework were also added: we refer to complexity (added by SAS) and decay (Lee, 2017). No regards to the number of V's or the confusion originating from the rapid evolution of the many proposed definitions of big data, it is important to understand data generation has seen tremendous growth in recent years, and the need to adjust data analysis capacities followed the same curve, an indication big data emerged from the need to process large amounts of data gathered (Gandomi \& Haider, 2015). In fact, the emergence and evolution of big data point toward a tremendous growth and availability of data that might be either sustained or accelerated in the near future (Hassani \& Silva, 2015).

\subsection{Big Data: Advantages and Disadvantages}

The appearance of the big data era generated hype among big companies, firms and businesses as they were all trying to apply big data to their respective activities with the objective of creating or realizing value from its use. Thus far, it sometimes appears unclear how organizations reap value from big data utilization (Günther, Mehrizi, Huysman, \& Feldberg, 2017); however, knowing and understanding the main advantages and disadvantages associated with big data application may help businesses, regardless of their size, decide whether to use/not use the popular technology. The decision to use big data and big data analytics should be based on the expected benefits a company or business wants to achieve from big data utilization. There are four known kinds of benefits associated with big data from an organizational standpoint: transactional, strategic, transformational and informational (Raguseo, 2018). Consumers' big data advantages are the focus of the present paper, which is why we will not extend on the benefits for companies. Some advantages and disadvantages consumers' experience in relation to big data technologies are discussed thereafter.

Big data creates the potential for companies to implement a personalized marketing system which yields better recommendations to consumers. Lee (2017) explained that companies exploit big data from multiples sources which allows them to deliver personalized products recommendations, services or promotional offers. This advantage is known as the recommendation system (ARE).

Internet technologies made information search (AIS) as easy as ever before. However, there would be no guarantee the information retrieved from a search would be accurate considering the tremendous availability of data. Big data technologies provide such accuracy, relevance and speed. No need to spend countless hours filtering search results, and the information retrieved from a consumer's browser is rather accurate. With the use of big data technologies, large amounts of data can be filtered in a matter of seconds to return the most accurate results (Liaw \& Le, 2017). But, although information is important, a deluge of information, accurate or not, may cause more harm than good and render the decision-making process harder. Butcher (1998) proposed of couple definitions of information overload, and one of them pointed at having more relevant information than one can possibly assimilate. Researchers found that obvious benefits exist from easier access to information, however information overload can generate problems such as stress, boredom and physical ill health (Edmunds \& Morris, 2000).

Big data helps companies set prices dynamically. Baker, Kiewell, and Winkler (2014) discussed how information collected from customers' interactions allowed businesses to set prices accordingly. It also helps businesses guarantee customers' satisfaction while optimizing prices (Lee, 2017). The individual-level price discrimination also known as dynamic pricing (ADP) became very common with internet marketing's development. Through the individual-level price discrimination, businesses can capture a larger share of consumers' surplus (Gabarino \& Lee, 2003). It is therefore possible to match each consumer's willingness to pay through the use of big data technologies leading to a maximized profit for sellers (Liaw \& Le, 2017). 
The use of big data allows companies to considerably improve customers' satisfaction. Big data analytics can be used to detect fraudulent activities and notify clients in real time. It also creates the ability to effectively assist customer service personnel in understanding and addressing customers' problems (Lee, 2017). It is important to keep in mind satisfied customers are important to any successful business, which is why businesses try by any means necessary to keep customers happy. Big data offers the means to do so through an improved customer service (ACS).

While customers experience big data advantages during their online experiences, they might as well express concerns closely related to the use of big data analytics by online service providers.

Upon visiting online platforms (tourism or any other e-commerce platform), customers' major concerns are the extensive collection of personal information and the security level related to data management. Users of online services are increasingly concerned about lack of proper security mechanism that might lead to confidential information being stolen, transmitted inadvertently or leaked because the use of big data technologies leads to tons of personal information being collected. Therefore, privacy and security constitute a major challenge organizations will have to think of while making the decision to use big data technologies because, not addressed, such a concern might scare away customers, and they'll be reluctant to provide any personal information.

Jorgenson and Hsiao (2016) argued that a behavior can become a source of addiction when performing an act leads to diminished control over the behavior despite adverse consequences. Individuals spending extended amount of time surfing the internet might develop different types of addictions: internet addiction, shopping addiction, etc. Throughout the literature, negative impacts from misuse or overuse of the internet are constantly discussed and include problems with mood, sleep, interpersonal relationship (Jorgenson \& Hsiao, 2016). Some authors believe the internet has aggravated the problem of information overload (Swash, 1998). The internet's influence is not to be neglected considering internet use is increasing on a global scale. Internet addicts will hardly log off from the internet and shopping addicts will try to secure all sorts of deals from the internet, needed or not.

Within group of people, trends are usually developed and most, if not all, individuals from the group will follow the trend. This is normally a good influence within a group. However, when the group's influence leads to a customer no longer expressing his own identity to cope with the group's ideology, it might become detrimental with time. If, at some point, the group is divided, such individual might be critically challenged to develop its own personality. Being part of a group should empower individuals rather than suppressing their personal identity.

\subsection{Online Tourism}

The concept of online tourism, also known as e-tourism, has seen the light of day with the development of internet and communication technologies (ICT). Pan (2015) defines it as this phenomenon where both tourists and organizations adopt ICTs. It is reported that progress in ICT have completely changed how business is conducted in the tourism industry considering how it places the final customer at the center of the production process (Porter, 2001; Condratov, 2013). Once the commerce industry adopted internet and communication technologies, due to the fact that processes and value chains in the industry were transformed by the integration of ICT, therefore the landscape changed (Buhalis, 2003). The internet plays an important role of facilitation and mediation between consumers and service providers in the tourism sector (Werthner \& Klein, 1999; Xiang \& Gretzel, 2010). Tourists can access tremendous amounts of information online, purchase products or services they are interested in, and share their personal opinion or experience via ratings, reviews or even personal blog posts. Information might be a very important commodity, however, having too much of it at one's fingertips may cause more harm than expected (Edmunds \& Morris, 2000). Business within the online tourism is conducted exclusively online, therefore it falls in the category of electronic commerce or e-commerce. Before the internet era, processes within the tourism industry were time consuming, from both the consumers and organizations standpoint: prices were not dynamic, information search was lengthy and had to be done through a travel agent, businesses had limited distributions channels to reach tourists. ICTs brought around new ways for customers to be reached and new distribution channels were created, leading to a redefinition of marketing and transformation of the tourism industry (Buhalis \& Law, 2008). Let's also note that online travels have pushed towards the development of new market dynamics and new behaviors considering that tourism in viewed as one of the most important components of e-commerce (Milano, Baggio, \& Piattelli, 2011).

\subsection{The Hierarchy of Effects Model}

The hierarchy of effects model was first introduced by St. Elmo Lewis in 1898 to explain the process through which a salesperson or marketing agent pushes the consumer to make the purchase decision. He first introduced 
a three steps hierarchical framework (attention, interest and desire) that he later updated, adding action as a fourth step (Barry, 2012). It is reported that the marketing and advertisement literature features many hierarchy of effects models which were developed in the personal selling literature since the development of the original model (Bambang, 2012).

Since the introduction of the original model attributed to Strong (1925), many different revisions, adaptations or extended versions have been proposed. At first, Lewis updated his model from attention, interest and desire to attention, interest, desire and action; then it took subsequent forms summarized by Barry \& Howard (1990) in their critique of the model in the advertising field. Researchers never stopped expressing interest in the model and, as of recently, a few more versions of the model were proposed in the literature; notably the SICAS model (Yan, Hu, Xu, \& Liu, 2017) developed in China in 2011 and the AISDALSLove model (Bambang, 2012). Previous researchers laid the ground for revisions of the model, which is why the present study is based on the assumption that more layers can eventually be added to the original model in order to study consumers' behavior in the online tourism field at a moment where big data and information technologies are very important to the tourism industry.

Travel and tourism websites should have the ability to draw consumers' attention, raise their interest, make them desire the offered products and lead them to the purchase decision. These are the four basic stages of the hierarchy of effects model. But, as social media use becomes more prominent, offering a high service quality tailored to the customer will satisfy his needs and he might end up sharing his experience by any means at his disposal. However, if the consumer is not satisfied and wants to voice his opinion, he will share his negative experience with his connections through word of mouth propagation or on social media to raise awareness among other peers as well as attract more attention to his case so that he can possibly get what he is looking for. To the contrary, a satisfied consumer will return a positive feedback on the service received and might be likely to repurchase from the seller and recommend the same service or package to his friends and peers.

Three moments exist in the travel process: before, during and after as discussed by Leung, Law, Hoof, and Buhalis (2013). Most of the information search is done before the trip when the customer is gathering all available and relevant information and tries to make a decision. Most of the sharing is often done during and after trip. During the trip, some of the information search continues as customers try to identify popular destinations and tourists' spots. Therefore, we have an idea of the moments in which the consumer might express certain layers of behavior such as attention, intention, etc.

From what precedes, the hypotheses that will guide the present study are formulated as follow while the relationship will be explored based on the model presented in Figure 1:

$H_{I}$ : There are more than two layers of consumer behavior in online tourism associated with big data technologies.

$\mathrm{H}_{2}$ : There is a relationship between big data advantages and online consumer behavior

$H_{3}$ : Each big data advantage is significantly associated with at least one layer of consumer behavior in online tourism

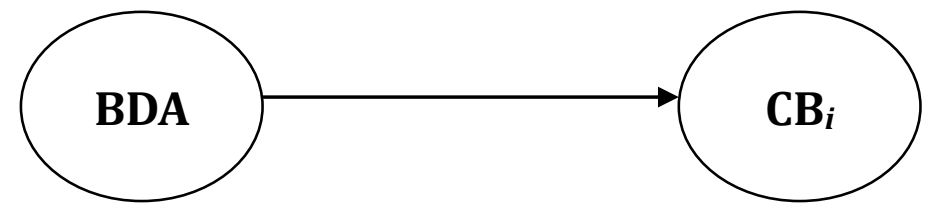

Figure 1. Study Model

\section{Methodology}

After consulting relevant literature to big data analysis, online tourism, consumer behavior both offline and online, a questionnaire was designed in order to collect appropriate online data to conduct the present study. To make sure the questionnaire is statistically correct, a first group of data $(\mathrm{N}=66)$ was collected from which the internal consistency was tested by determination of Cronbach's alpha $(\alpha)$. An alpha $(\alpha)$ value greater than 0.7 indicates a high internal consistency whereas between 0.5 and 0.7 the internal consistency of the variables can still be accepted (Augustin \& Liaw, 2017). The pilot test did not reveal any incoherencies; therefore, data collection was resumed. 


\subsection{Data Collection}

This study required the use of online questionnaires. To make sure respondents would have a clear understanding of the content; two videos were provided at the beginning of the questionnaire as well as a short and quick introduction of the concept big data by the authors. The questionnaire's link was posted on social media platforms such as Facebook and Instagram to ensure a large diversity among the respondents. The ability to fill out the questionnaire remained for about three months between August and October 2018.

\subsection{Sample Size and Measurements}

Over 300 respondents filled out the questionnaires between August and October 2018. The data examination procedure revealed the existence of univariate outliers within the dataset. Hair (2014) defined outliers as an observation substantially different because it likely has an extreme value. Overall, 45 outliers were detected and therefore the 260 remaining questionnaires were considered suitable to proceed with the analyses. Due to the lack of significance to the study, the demographic characteristics of the sample were not further investigated but will be presented at a later point.

The questionnaire was divided into four sections: the first and second sections measured respondents' perception regarding big data advantages and disadvantages respectively, the third one measured consumers' behavior towards big data advantages and the fourth assessed demographic characteristics such as gender, age, education and so forth. A 7-point Likert scale ranging from strongly disagree (1) to strongly agree (7) was used in the questionnaire.

\subsection{Characteristics of the Sample}

A total of 305 questionnaires were returned after completion of the data collection process. All questionnaires were fully completed and, after the dataset have been examined and screened for univariate outliers, 45 questionnaires were not considered. The analyses were conducted with the remaining 260 questionnaires. Table 1 presents the characteristics of the sample.

Table 1. Demographic Characteristics $(n=260)$

\begin{tabular}{cccc}
\hline Variables & Valid & Frequency & Percentage (\%) \\
\hline \multirow{2}{*}{ Gender } & Male & 92 & 35.4 \\
& Female & 168 & 64.6 \\
\hline \multirow{2}{*}{ Age } & Less than 20 & 105 & 40.4 \\
& 21 to 25 & 83 & 31.9 \\
& 26 to 35 & 44 & 16.9 \\
\hline \multirow{2}{*}{ Education Level } & 36 to 50 & 28 & 10.8 \\
& High school or Vocational & 8 & 3.1 \\
& Bachelor & 203 & 78.1 \\
\hline
\end{tabular}

\subsection{Data Analysis}

Statistical Package for Social Sciences (SPSS 22.0), AMOS 22.0 and STATISTICA 13 were used to conduct statistical analyses. Various analyses are included in the present study: the calculation of Pearson's correlation coefficient, an internal consistency study through the calculation of Cronbach's alpha, an exploratory factor analysis is conducted to identify the factors' structure of online consumer behavior in the context of big data advantages in online tourism, regression analyses as well as a structural equation modeling, were also conducted in order to identify which advantages are specific to the layers of online consumer behavior.

\section{Results and Discussions}

This section discusses the results of our analyses where factors of consumers' behavior based on consumers' responses applied to an online tourism context are identified through factor analysis. Further analyses were conducted to identify big data advantages related to each layers of behavior.

\subsection{Structure Identification and Model Building}

The 14 items of consumer behavior designed based on relevant literature had their factorability examined. First, it was observed that the 14 items significantly correlated between $0.160^{* *}$ and $0.656^{* *}$ with one other item, suggesting reasonable factorability. Second, the Kaiser-Mayer-Olkin measure of sampling adequacy was 0.887 , 
above the commonly recommended value of 0.6 and Bartlett's test of sphericity (used to explore the presence of correlations between variables) was statistically significant $(\mathrm{p}=0.000)$ thus indicating sufficient correlations between the variables to proceed with the exploratory factor analysis (Hair, Black, Babin, \& Anderson, 2014). Finally, the communalities were all above 0.5 , further confirming that each item shared some common variance with other items. Based on the previously mentioned indicators, factor analysis was considered suitable with all 14 items.

Principal component analysis with varimax rotation was used considering the primary goal was to identify the factors representative of consumers' behavior in the online tourism context. Based on eigenvalues and scree plot criteria, the solution with three factors was considered suitable with the factors having respectively the following eigenvalues of $6.514,1.440$ and 1.100 . The three factors solution explained $64.67 \%$ of the variance, with the first, second and third factor explaining respectively $46.53 \%, 10.29 \%$ and $7.85 \%$ of variance. This solution was deemed suitable because all other factors had an eigenvalue lower than 1 and did not explain a substantial part of the variance making it hard to interpret subsequent factors. No items were eliminated as they all contributed to a factor structure and met the minimum criteria of having a primary factor loading of 0.4 or above (Hair et al., 2014).

Finally, after all rotation methods were tested and varimax rotation was deemed the most appropriate, the factor analysis conducted with all 14 items constituting online consumer behavior revealed the three factors structure explaining $64.67 \%$ of variance as mentioned earlier. Therefore, three layers of consumer behavior were identified from the results. The first, second and third layers of consumers' behavior are named AI (attention and intention), DA (desire and action) and SS (sharing and social awareness). Table 2 presents the items of each factor. Let's note factor loadings lower than 0.5 were hidden because the intent is to only display the primary contributors to each factor.

Overall, the analysis' results indicated three distinct factors underlying online consumers' behavior when it comes to big data advantages applied in the online tourism context. Internal consistency for each scale was examined using Cronbach's alpha. The reliability of each scale was satisfying: 0.769 for AI (4 items), 0.862 for DA (4 items) and 0.850 for SS (6 items). As observed from the "Cronbach's alpha if item deleted" function in the SPSS software, no substantial increases in alpha for any of the scales could have been achieved by removing more items.

Table 2. Varimax-rotated component analysis factor matrix

\begin{tabular}{ccccc}
\hline & \multicolumn{3}{c}{ Factor loadings } & \\
\cline { 2 - 4 } & SS & DA & AI & \\
\hline BS1 & 0.791 & & & 0.653 \\
BS2 & 0.616 & & & 0.618 \\
BS3 & 0.855 & & & 0.759 \\
BS4 & 0.611 & & & 0.618 \\
BS5 & 0.530 & & & 0.630 \\
BS6 & 0.501 & & & 0.515 \\
Bac1 & & 0.749 & & 0.654 \\
Bac2 & & 0.766 & & 0.713 \\
BDe1 & & 0.752 & & 0.696 \\
BDe2 & & 0.834 & & 0.748 \\
BIn1 & & & 0.652 & 0.605 \\
Bin2 & & & 0.840 & 0.734 \\
BAt1 & & & 0.512 & 0.536 \\
BAt2 & & & 0.675 & 0.573 \\
\hline
\end{tabular}

\subsection{Nature of the Proposed Model}

The proposed extended hierarchy of effects for consumer behavior in online tourism is a second order reflective 
model where the direction of the causality is from construct to items considering they covary with each other and dropping or adding one indicator would not modify the conceptual domain of the construct (Akter \& Hani, 2011). Edwards and Bagozzi (2000) noted that measures are considered reflective when they are used to examine an underlying construct that is observable. To ensure reflective measures are reliable, internal consistency is important; therefore Cronbach's alpha as well as other reliability measures are suitable for reliability assessment (Petter, Straub, \& Rai, 2007). Bollen and Lennox (1991) reported that "the correlation between any two measures should be positive for reflective constructs".

The research model for online consumer behavior in the case of big data applied in online tourism therefore is presented in Figure 3 based on the analyses results:

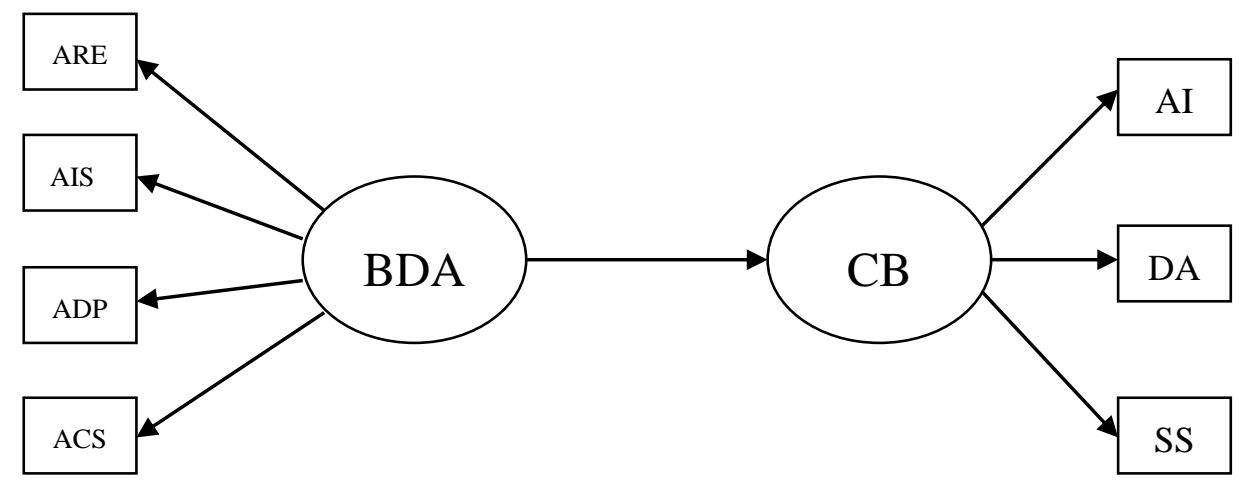

Figure 2. Relationship between BDA and CB

A previous research from Liaw and Le (2017) supports the existence of the first two layers (AI and DA); but SS is a new measurement being added to the basic framework of the hierarchy of effects model. Consumers, after making the purchase decision of goods and services online, they no longer just enjoy the experience. The social media age has given a voice to consumers who can either express their satisfaction or lack of satisfaction, based on their experience. In case of a positive experience, the consumer will often share the outcome with his peers and friends on social media, review, rate and comment on the e-vendor's website and likely repurchase from that e-vendor. If the experience was not pleasant, he will actively try to return the product or get a refund, post negative comments, poor reviews and ratings on the e-vendor's site in order to let others know what they are dealing with. In both situations, it is their way of raising social awareness. These comments, reviews and ratings posted on the e-vendor's page will remain on the website and other prospective customers can access them while they are simply checking products or about to make the purchase decision.

\subsection{Sharing and Social Awareness: A Social Media Gift}

Knowledge sharing has been continuously studied in the literature. There are many reasons for sharing in the field of travel and tourism and various studies emphasized some of these reasons (Bilgihan, Barreda, Okumus, \& Nusair , 2016). This opportunity has been granted to consumers with the introduction and diffusion of the interactive Web 2.0 (named Travel 2.0 in the tourism field) features and applications. Online social networks are part of the Web 2.0. Social media platforms are seen as internet-based applications carrying user-generated contents created by consumers from relevant experience, and archived or shared online for easy access by other impressionable consumers (Blackshaw, 2006; Xiang \& Gretzel, 2010). Social media plays an ever increasing important role as an information source for travelers. In the Cluetrain Manifesto, it is asserted that "people in networked markets have figured out they get far better information and support from one another than from vendors" (Locke, Levine, Searls, \& Weinberger, 2000). This indicates user-generated contents are, more often than not, considered reliable (Ankehurst, 2009; Xiang \& Gretzel, 2010). Because they are viewed by other potential consumers as more reliable, and because consumers are more likely to believe a fellow customer who experienced a product or service, user-generated contents need to be given proper consideration. Xiang and Gretzel (2010) commented that "social media are becoming more popular, comprehensive and travel-specific sites are likely to evolve into primary online travel information sources". Therefore, tourism marketers can no longer ignore the role of social media in distributing travel-related information without the risk to become irrelevant (Milano et al., 2011). Besides the important role of social media in travel-related information search, it is important to understand social media platforms provide the consumers with a mean to make their voices heard either when they are happy about their experiences or disappointed by a service they paid for or by a service 
provider's customer care. Although many researchers discussed the sharing of information in online social networks, very rarely has it been considered for extension of the behavioral hierarchy model. Three layers of behavior have been identified, therefore $\mathrm{H}_{1}$ is supported.

\subsection{Relationship between Big Data Advantages and Online Consumers' Behavior}

Now that the layers of behavior have been identified, and it has been established that consumers' behavior follows a three layer structure, it is important to examine the existence of a relationship between the constructs. Using the structural equation model method, it is shown there is a direct positive and significant relationship between big data advantages and online consumers' behavior $\left(\mathrm{H}_{2}\right.$ : $\left.\beta 1=0.576, \mathrm{t}=10.438, \mathrm{p}<0.001\right)$ which indicated that $\mathrm{H}_{2}$ was supported. In other words, it means that consumers' behavior is likely to be influenced if they feel the advantages of big data applied in online tourism websites. Such result is consistent with previous studies from Liaw and Le (2017).

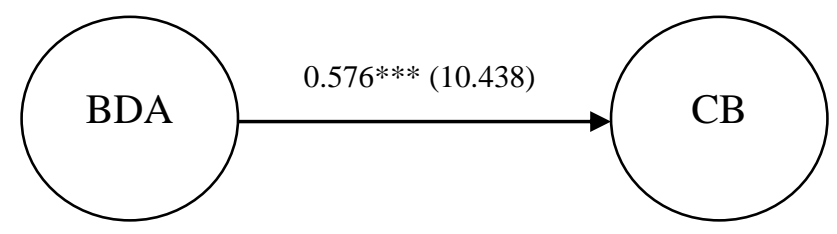

Figure 2. Direct effect between BDA and CB

\subsection{Strength of Behavior}

The one question that remains to be addressed after the composition of online consumer behavior and the existence of a relationship between the constructs have been figured out: how does the consumer really behaves whether he strongly or fairly feels the advantages of big data? In order to assess the strength of consumers' behavior depending on how they experience the advantages of big data in their online tourism experience, an analysis of variance was conducted and it yielded out the following results where the consumers highly feel the advantages of big data in their online tourism experience $(\mathrm{H})$ or fairly feel the advantages of big data in their online tourism experience (L). The combined effect of big data advantages and behavior came out significant (F: $3.19, \mathrm{p}<0.05)$ as seen in Figure 4.

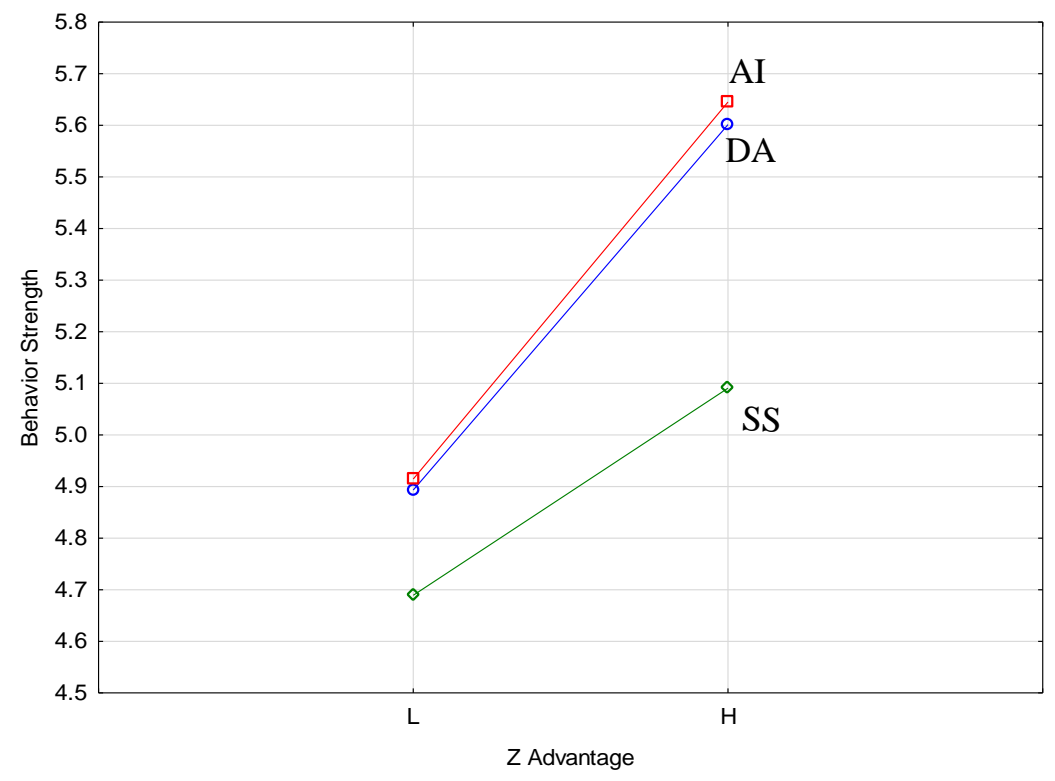

Figure 3. Strength of behavior vs. big data advantages

The more a customer feels the advantages of big data during his online tourism experience, the more likely he is to pay attention, express interest and desire, which might ultimately lead to him taking actions in the meaning of making the purchase decision. Compared to customers who feel the high advantages of using big data in online tourism, the category of customers who feel low advantages of using big data in online tourism will be less likely to pay attention, express their intention and desire, and take action and then share in order to raise social 
awareness. In other words, their behavior will be influence by their perception of big data advantages because the higher the perception is about the advantages of using big data in online tourism, the stronger the behavior will be.

\subsection{Relationship between Each Big Data Advantage and the Layers of Behavior}

First and foremost, before running a regression analysis in order to identify which specific big data advantage relates to which consumers' behavior component, it is important to explore the correlations between both constructs although not providing any insight on the causality of the relationship. Mendenhall \& Sincich (2012) specifically noted there is one valid conclusion to be drawn from the correlation, whether high or low, it is the possible existence of a linear trend between independent and dependent variables. The correlations are assessed using Pearson's correlation coefficient $\boldsymbol{r}$ (Table 3).

Table 3. Correlation between big data advantages and consumers' behavior

\begin{tabular}{ccccccc}
\hline Variables & Mean & Std. & ARE & AIS & ADP & ACS \\
\hline AI - Attention - Intention & 5.2827 & 0.86317 & $0.316^{* *}$ & $0.453^{* *}$ & $0.425^{* *}$ & $0.454^{* *}$ \\
DA - Desire - Action & 5.3163 & 0.85151 & $0.414^{* *}$ & $0.488^{* *}$ & $0.488^{* *}$ & $0.396^{* *}$ \\
SS - Sharing - Social awareness & 4.9103 & 0.93335 & $0.213^{* *}$ & $0.296^{* *}$ & $0.266^{* *}$ & $0.279^{* *}$ \\
\hline
\end{tabular}

**. Correlation is significant at the 0.01 level (2-tailed).

From the correlation table, it is observed that all correlations are significant, although not strongly correlated to one another. As noted by Augustin and Liaw (2017), we can assess the strength of a linear relationship between two correlated variables with the calculation of the correlation coefficient $\boldsymbol{r}$. Of all the layers of consumer behavior, SS is the one displaying the weakest correlations with all of the big data advantages regardless of their significance level. It is clear that all the correlations are significant, but this might be partly explained by the fact that not all customers care or feel compelled to sharing their experience on social media, might want to keep some experiences for themselves, only share when they have a negative experience or might not even know about social media in some cases.

Once the correlations between big data advantages and layers of online consumer behavior have been explored, it is important to figure out which advantage is significant to which layer of behavior. For this to be accomplished, the relationship between the advantages and each layer of behavior will be studied closely through regression analysis.

The regression analyses exploring the relationship between every single big data advantage and the different layers of consumer behavior in the context of big data applied in online tourism resulted in Table 4. Let's note the advantages are the independent variables whereas behavior is the dependent variable.

Table 4. Relationship between layers of behavior and big data advantages

\begin{tabular}{cccccc}
\hline Constant $\left(\beta_{\mathrm{o}}\right)$ & ARE & AIS & ADP & ACS & Behavior (CB) \\
\hline 2.204 & $0.261^{* * *}$ & $-0.185^{*}$ & 0.110 & $0.514^{* * *}$ & AI \\
1.428 & 0.093 & $0.247^{* *}$ & $0.214^{* *}$ & $0.157^{*}$ & DA \\
2.850 & 0.086 & -0.038 & 0.008 & $0.348^{* * *}$ & SS \\
\hline
\end{tabular}

Note. $* * * \mathrm{p}<0.001, * * \mathrm{p}<0.01, * \mathrm{p}<0.05$

A customer, in his online experience will be more likely to express attention and intention as he feels the advantages of a recommendation system $\left(0.261^{* * *}\right)$ and an improved assistance to customers $\left(0.514^{* * *}\right)$. At a lesser degree, he might express attention and intention as he feels the advantages of an information search $\left(-0.185^{*}\right)$. However, the negative sign attached might indicate that the customer will, at some point, feel overwhelmed because as he experiences the information search function, he might end up spending more time reviewing information that aren't relevant to him. Polic (2009) reported that too much information, multiple information sources, incomplete or conflicting information are considered stressors that will lead to decision making being made in stressful conditions. Therefore, the overwhelming amount of information will not benefit the consumer both in terms of time spent reviewing inappropriate offers and in decision-making being made under stress. It has also been discussed that accurate and precise information is important for decision-making; however, too much information or many information sources, relevant or not, lead to information overload and the consequences of information overload are well known and include (but are not limited to) stress, physical ill 
health, boredom, slower decision-making (Butcher, 1998; Edmunds \& Morris, 2000; Hemp, 2009). Information should be precise and filtered down for the consumer otherwise there is the risk that it may become a disadvantage. After the first stage where the customer expresses attention and intention, he then moves to the desire and action stage where the purchase decision is made. He is very likely to express desire and make the purchase decision as he feels the advantages of an information search $(0.247 * * *)$ and dynamic pricing $(0.214 * * *)$ functions. Once the relevant information is found, the customer expresses desire and even takes action. At a lesser degree, the customer might express desire and take action when he feels the advantages of an improved assistance to customer $(0.517 *)$. Once the customer has been taken care of (either well or not well), he is very likely to share his opinion as well as raise social awareness. This third stage where the customer might feel the advantage of an improved assistance to customers $\left(0.348^{* * *}\right)$ is critical for e-vendors because a satisfied customer will share his positive opinion based on his online experience. The same way, if the customer is not satisfied, he will return negative feedback, give negative ratings, post about his negative experience on social media and discourage his surroundings to buy from the e-vendor who provided the poor service. Other customers can later access those comments and opinions, and in some situations said comments/opinions, if negative and considered meaningful, might turn new customers off when it comes to buying from this e-vendor.

Organizations and businesses will take away from the research findings the importance of sharing between customers in the e-commerce filed. Consumers often share their negative experiences with peers; they are also likely to recommend any e-vendor from whom they received a high quality service. Therefore, satisfied consumers are assets they should manage to always have on their side. Moreover, tremendous amounts of information might become detrimental to decision-making. Providing customers with specific, concise and very accurate information about products and services might serve them well.

\section{Conclusion}

The last three decades saw numerous information and communication technology developments among which are listed the apparition of the internet and the emergence of social media. With these developments, tremendous amounts of data are generated on a daily basis. That led to the rise of the concept of big data. Big data, with the opportunities and challenges that it brings, impacts all businesses and industries, including the tourism industry. The present study was conducted to extend the hierarchy of effects model as a mean to adapt it to big data applied in online tourism, to explore the relationship between big data advantages and consumers' behavior and to figure out how layers of behavior are influenced by big data's advantages. The results showed the integration of a third layer in the hierarchy of effect model. It is indicative of the penetration of social media into the tourism field. Big data advantages are significantly correlated to the layers of behavior in online tourism, although the significance levels are not the same as shown in the results section. The new layer deals with the important issue of sharing in online tourism. Integrating new concepts brought around by recent technology developments is at the core of extending models that were developed in the past to deal with current issues. Consumers' behavior is, and will remain an important topic because individuals constantly change their behavior depending on the situation. Xiang and Gretzel (2010) emphasized because tourism rely so much on information, it is important to fully understand technological changes impacting distribution and accessibility of travel information. But, as discussed earlier, companies need to be aware of the disadvantages of information overload on consumers' decision-making.

\section{Limitation and Future Research}

Further studies might attempt to introduce new measurements to deal with recent developments of ICTs considering that tourism is mutually affected by new technologies. For example, mobile technologies are further changing the structure of communication and how business is conducted. This is an opening for more studies in the field.

\section{References}

Akter, S., \& Hani, U. (2011). Complex modelling in marketing using component based SEM. Australian and New Zealand Marketing Academy Conference, 1-9.

Ankehurst, G. (2009). User generated content: the use of blogs for tourism organizations and tourism consumers. Service Business, 3(1), 51-61. https://dx.doi.org/10.1007/s11628-008-0054-2

Augustin, J. L. P. M., \& Liaw, S. Y. (2017). Tourism Competitiveness of the Asia-Pacific Region through Consistency Analysis. Asia-Pacific Journal of Tourism Research, 22(12), 1295-1307. https://doi.org/10.1080/10941665.2017.1391855

Baker, W., Kiewell, D., \& Winkler, G. (2014, June). McKinsey. Retrieved April 6, 2020, from http://www.mckinsey.com/business-functions/marketing-and-sales/our-insights/using-big-data-to-make-bett 
er-pricing-decisions

Bambang, S. (2012). The Development of Hierarchy of Effects Model in Advertising. International Research Journal of Business Studies, 5(1), 73-85. https://doi.org/10.21632/irjbs.5.1.73-85

Barry, T. E. (2012). The development of the Hierarchy of Effects: An Historical Perspective. Current Issues and Research in Advertising, 10(1-2), 251-295.

Barry, T. E., \& Howard, D. J. (1990). A Review and Critique of the Hierarchy of Effects in Advertising. International Journal of Advertising, 9(2), 98-111. https://doi.org/10.1080/02650487.1990.11107138

Bilgihan, A., Barreda, A., Okumus, F., \& Nusair, K. (2016).Consumer Perception of Knowledge Sharing in Travel-Related Online Social Networks. Tourism Management, 52, 287-296. https://doi.org/10.1016/j.tourman.2015.07.002

Blackshaw, P. (2006). The consumer-generated surveillance culture. Retrieved from http://www.clickz.com/showPage.html?page=3576076

Bollen, K., \& Lennox, R. (1991). Conventional Wisdom on Measurement: A Structural Equation Perspective. Psychological Bulletin, 110(2), 305-314. https://doi.org/10.1037/0033-2909.110.2.305

Buhalis, D. (2003). E-tourism: Information Technology for Strategic Tourism Management. London: Pearson (Financial Times / Prentice Hall).

Buhalis, D., \& Law, R. (2008). Progress in information technology and Tourism Management: 20 years on and 10 years after the internet: The state of e-Tourism research. Tourism Management, 29, 609-623. https://doi.org/10.1016/j.tourman.2008.01.005

Butcher, H. (1998). Meeting Managers' Information Needs. London: Aslib.

Chen, H., Chiang, R., \& Storey, V. C. (2012). Business Intelligence and Analytics: From Big Data to Impact. MIS Quarterly, 36(4), 1165-1188. https://doi.org/10.2307/41703503

Condratov, I. (2013). E-Tourism: Concept and Evolution. Ecoforum, 2(1), 58-61.

Constantiou, I. D., \& Kallinikos, J. (2015). New Game, New Rules: Big Data and the Changing Context of Strategy. Journal of Information Technology, 30(1), 44-57. https://doi.org/10.1057/jit.2014.17

Edmunds, A., \& Morris, A. (2000). The Problem of Information Overload in Business Organizations: A Review of the Literature. International Journal of Information Management, 20(1), 17-28. https://doi.org/10.1016/S0268-4012(99)00051-1

Edwards, J., \& Bagozzi, R. (2000). On the Nature and Direction of Relationships between Constructs and Measures. Psychological Methods, 5(2), 155-174. https://doi.org/10.1037/1082-989X.5.2.155

Gabarino, E., \& Lee, O. (2003). Dynamic pricing in internet retail: effects on consumer trust. Psychology and Marketing, 20(6), 495-513. https://doi.org/10.1002/mar.10084

Gandomi, A., \& Haider, M. (2015). Beyond the hype: Big data concepts, methods, and analytics. International Journal of Information Management, 35(2), 137-144. https://doi.org/10.1016/j.ijinfomgt.2014.10.007

Günther, W. A., Mehrizi, M. H., Huysman, M., \& Feldberg, F. (2017). Debating Big Data: A Literature Review on Realizing Value from Big Data. Journal of Strategic Information Systems, 26, 191-209. https://doi.org/10.1016/j.jsis.2017.07.003

Hair, J. J., Black, W. C., Babin, B. J., \& Anderson, R. E. (2014). Multivariate Data Analysis: Pearson New International Edition (7th ed.). Edinburgh: Pearson Education Livited.

Harteveldt, H., Stark, E., Sehgal, V., \& van Geldrn, K. (2009). US Online Leisure Travel channel Share Forecast: Suppliers vs Intermediaries: 2008 to 2013. Cambridge: Forrester Research.

Hassani, H., \& Silva, E. S. (2015). Forecasting with Big Data: A Review. Annals of Data Science, 2, 5-19. https://doi.org/10.1007/s40745-015-0029-9

Hemp, P. (2009). Death by Information Overload. Havard Business Review, 87(9), 83-89.

Jorgenson, A., \& Hsiao, R. J. (2016). Internet Addiction and Other Behavioral Addictions. Child and Adolescent Psychiatric Clinics of North America, 509-520. https://doi.org/10.1016/j.chc.2016.03.004

Kwon, O., Lee, N., \& Shin, B. (2014). Data Quality Management, Data Usage Experience and Acquisition Intention of Big Data Analytics. International Journal of Information Management, 34(3), 387-394. https://doi.org/10.1016/j.ijinfomgt.2014.02.002 
Laney, D. (2001). 3D Data Management: Controlling Data Volume, Velocity and Variety. Application Delivery Strategies, 949.

Lee, I. (2017). Big data: Dimensions, evolution, impacts, and challenges. Business Horizons, 60, 293-303. https://doi.org/10.1016/j.bushor.2017.01.004

Leung, D., Law, R., Hoof, H., \& Buhalis, D. (2013). Social Media in Tourism and Hospitality: A literature review. Journal of Travel \& Tourism Marketing, 30, 3-22. https://doi.org/10.1080/10548408.2013.750919

Liao, Z., Yin, Q., Huang, Y., \& Sheng, L. (2014). Management and application of mobile big data. International Journal of Embedded Systems, 7(1), 63-70.https://doi.org/10.1504/IJES.2015.066143

Liaw, S. Y., \& Le, T. (2017). Effects of Pros and Cons of Applying Big Data Analytics to Consumers' Responses in an e-Commerce Context. Sustainability, 9, 1-19. https://doi.org/10.3390/su9050789

Locke, C., Levine, C., Searls, D., \& Weinberger, D. (2000). The Cluetrain Manifesto: The end of business as usual. Cambridge, MA: Perseus Publishings. https://doi.org/10.1145/334425.334443

Mendenhall, W., \& Sincich, T. (2012). A Second Course in Statistics Regression Analysis (7th ed.). Boston: Pearson.

Milano, R., Baggio, R., \& Piattelli, R. (2011). The Effects of Online Social Media on Tourism Websites. 18th Conference on Information Technology and Travel and Tourism. January 26-28, 2011. Innsbruck, Austria: ENTER2011.https://doi.org/10.1007/978-3-7091-0503-0_38

Pan, B. (2015). Encyclopedia of Tourism. New York: Springer.

Petter, S., Straub, D., \&Rai, A. (2007). Specifying formative constructs in IS research. MIS Quarterly, 31(4), 657-779. https://doi.org/10.2307/25148814

Polic, M. (2009). Decision Making: between rationality and reality. Interdisciplinary Description of Complex Systems, 7(2), 78-89.

Porter, M. (2001). Strategy and the Internet. Havard Business Review, 3(79), 63-78.

Raguseo, E. (2018). Big Data Technologies: An Empirical Investigation on their Adoption, Benefits and Risks for Companies. International Journal of Information Management, 187-195. https://doi.org/10.1016/j.ijinfomgt.2017.07.008

Shah, T., Rabhi, F., \& Ray, P. (2015). Investigating an ontology-based approach for big data analysis of inter-dependent medical and oral health conditions. Cluster Computing, 18(1), 351-367. https://doi.org/10.1007/s10586-014-0406-8

Strong, E. K. (1925). The psychology of Selling and Advertising. New York: McGraw-Hill.

Swash, G. (1998). UK Business on the Internet. New Library World, 99(1144), 238-242. https://doi.org/10.1108/03074809810236793

Werthner, H., \& Klein, S. (1999). Information Technology and Tourism: A challenging relationship. Vienna: Springer. https://doi.org/10.1007/978-3-7091-6363-4

Xiang, Z., \& Gretzel, U. (2010). Role of Social Media in Online Travel Information Search. Tourism Management, 31, 179-188. https://doi.org/10.1016/j.tourman.2009.02.016

Yan, X. X., Hu, Z. Q., Xu, J., \& Liu, J. Y. (2017). Research on the Social e-Commerce Marketing Model Based on SICAS Model in China. International Journal of Marketing Studies, 9(3), 113-123. https://doi.org/10.5539/ijms.v9n3p113

Zhong, R., Newman, S., Huang, G., \& Lan, S. (2016). Big Data for supply chain management in the service and manufacturing sectors: Challenges, opportunities, and future perspectives. Computers \& Industrial Engineering, 101, 572-591.https://doi.org/10.1016/j.cie.2016.07.013

Zicari, R. (2013). Big Data: Challenges and Opportunities. In R. Akerkar, Big Data Computing (pp. 564). New York: Chapman and Hall / CRC. https://doi.org/10.1201/b16014

\section{Copyrights}

Copyright for this article is retained by the author(s), with first publication rights granted to the journal.

This is an open-access article distributed under the terms and conditions of the Creative Commons Attribution license (http://creativecommons.org/licenses/by/4.0/). 